\title{
Escola, currículo e conhecimentos: sentidos tensionados em contextos da pandemia
}

\begin{abstract}
Resumo: No texto, se analisam alguns sentidos sociais atribuídos às escolas, currículos e conhecimentos nesse tempo de pandemia, especialmente em razão da proposição de modelos não presenciais para o ensino. Nesse âmbito, discute-se correlações de força que vêm sendo mobilizadas por distintos grupos ou segmentos sociais ligados à educação, os quais buscam marcar concepções e interesses visivelmente distintos no debate sobre sentidos e finalidades para a formação escolar. Trata-se de um trabalho de base empírico-teórica, que explora como fontes: documentos oficiais, textos acadêmicos e informações da imprensa disponibilizados em ambientes digitais. Afirma-se que esse jogo de forças coloca em disputa três racionalidades: uma de base neoliberal que concebe a escola como máquina de produção de resultados objetivos, outra ancorada na ideia de escola como espaço socioeducativo, portanto, de redução de desigualdades, e uma terceira que entende a escola como lugar de formação humana e instituição promotora do direito universal à aprendizagem e ao desenvolvimento humano.
\end{abstract}

Palavras chave: Ensino. Currículo. Conhecimento. Pandemia.

\section{Introdução}

Entre as incontáveis perguntas que grupos sociais, instituições e pessoas fazem a si mesmas e ao mundo nesse tempo de excepcionalidade, estão as que dizem respeito a educação e que, portanto, são de especial interesse para docentes e pesquisadores que militam nesse campo. Em geral, se observa que questões mobilizadas com evidência em redes sociais, na grande mídia e na própria academia são, de algum modo, as que atravessam o histórico debate da educação em geral e, em particular, da escola e seus currículos, especialmente neste momento de pandemia quando são colocados face-to-face os antagonismos entre a economia, a política, a formação humana e a vida. Nossa hipótese é que as tantas perguntas possam ser acolhidas em apenas uma de caráter amplo, sobre a qual nos ocuparemos no texto e que está formulada nos seguintes termos. Que sentidos sociais estão sendo atribuídos à escola, aos currículos e aos conhecimentos nesse contexto que desafia estados e sociedade civil no enfrentamento da pandemia?

Essa abarcadora indagação já vem sendo pautada em meio a um conjunto de problemáticas próprias do debate curricular iniciadas desde a constituição desse campo de estudos no início do século
Juares da Silva Thiesen Universidade Federal de Santa Catarina - UFSC juares.thiesen@ufsc.br 
$\mathrm{XX}$ e ainda sem consenso em termos de resposta. Assim, o desafio de retomá-la deve ser entendido pelos leitores como um esforço a mais no sentido que situar a discussão nesse momento específico de enfrentamento social da pandemia de COVID-19. Um desafio que, no âmbito da educação, vem sendo tensionado por discursos e proposições que se colocam em defesa de alternativas operacionais e instrumentais visando manter a máquina escolar funcionando sem interrupção, em contraposição à concepções que seguem na resistência, disputando modelos de formação escolar ancorados em princípios e métodos pedagogicamente reconhecidos.

A defesa assumida por significativa parcela de grupos ligados à produção econômica e ao mercado pela manutenção do funcionamento de escolas e universidades durante esse tempo de isolamento social, por meio de alternativas metodológicas, em alguns casos, pedagogicamente pouco referenciadas, revela que não há mesmo consenso em relação aos sentidos e finalidades sociais de escola, de currículo e de conhecimento. Supõe-se, assim, que $\mathrm{o}$ atendimento às demandas formais de âmbito administrativo e burocrático podem, por um amplo leque de interesses, se sobrepor as finalidades humanas da formação em termos de aprendizagem e desenvolvimento. Entendemos que essa é a principal correlação de forças em operação nesse momento no debate educacional no Brasil.

O propósito assumido no trabalho é, portanto, discutir sobre essa correlação de forças mobilizadas por determinados grupos sociais, seja visando instituir dinâmicas e modos de funcionamento não convencionais às escolas nesse tempo de pandemia, seja tentando garantir alguns princípios formativos de base científica e pedagógica. São movimentos que, assumindo concepções e interesses visivelmente distintos, tensionam ainda mais o debate sobre sentidos e finalidades sociais da formação escolar. Assim, a premissa sobre a qual argumentamos é que na tentativa de protagonizarem certos fechamentos discursivos em torno da adoção (ou não) de modelos alternativos para a oferta de atividades escolares nesse tempo de pandemia, mais que tensionar a pauta do calendário letivo, grupos operam para fixar determinados sentidos e finalidades para escola, currículos e conhecimentos.

Observando-se o que vem sendo produzido no atual cenário brasileiro em termos de legislação educacional (BRASIL, 2020a; BRASIL, 2020b) e matérias da imprensa em geral (PAIXÃO, 2020; 
PALHARES, 2020), pode-se afirmar que há evidentes tentativas de hegemonização discursiva com sentidos notadamente distintos, cada qual, buscando reconhecimento social de suas concepções e interesses. Nesse jogo discursivo, as proposições giram, por um lado, em torno da imprescindibilidade do funcionamento imediato das atividades de ensino e da importância de novos modelos didático-pedagógicos baseados em tecnologia, e por outro, da necessidade de maior cautela, seja pela observância aos princípios pedagógicos, seja para evitar-se riscos de precarização da formação escolar. A seu modo, cada uma dessas formações discursivas, tenta fechar determinados sentidos para escola, currículo e conhecimento.

A exploração da base documental antes referida, de modo geral, aponta que as articulações discursivas mais evidentes indicam haver tentativas de significação, ou fechamento de sentidos, na direção de pelo menos três racionalidades amplamente conhecidas no campo da educação ${ }^{1}$. Uma delas é construída sobre a ideia de escola como máquina ${ }^{2}$ ou equipamento público de produção de resultados social e economicamente úteis, que na pandemia tende a acolher abertamente alternativas tecnoburocratizantes ${ }^{3}$ sustentadas por tecnologias de ensino remoto. Uma segunda é protagonizada por discursos em torno da ideia de uma escola de fundo socioeducativo, conceito que opera nas interfaces entre o atendimento ao direito subjetivo dos estudantes às aprendizagens escolares e as demandas sociais, especialmente as decorrentes do acesso às condições básicas de vida e mercado de trabalho. Grupos que se articulam em torno desse fechamento discursivo, tendem a acolher modelos alternativos de ensino (remoto, por exemplo), contanto que sejam relativamente inclusivos tanto para estudantes quando para famílias e trabalhadores.

A terceira racionalidade tem base discursa construída sobre a concepção de escola como espaço público, interativo, dinâmico e complexo, um direito universal à aprendizagem e ao desenvolvimento humano. Grupos que defendem essa concepção, tendem a desconfiar da oferta de modelos alternativos em larga escala, resistindo às formas instrumentais de ensino remoto para manutenção de calendários escolares, mesmo nesse tempo de excecionalidade. Enquanto os dois primeiros articulam estratégias discursivas para consolidar o reconhecimento social de modelos não presenciais de escolarização, este último segue fazendo resistência e elaborando
(1) Discussão mais ampla sobre as racionalidades destacas no texto pode ser encontrada em trabalhos como: Galvão (2017), Tragtenberg (2018), Russo (2016), Saviani (2000), Giroux (1986).

(2) A expressão escola como máquina foi utilizada tanto por Foucault quanto por Deleuze. (3) O conceito de tecnoburocracia é discutido, entre outros autores, por José Jorge Gebara no texto: "Algumas considerações sobre o estado, a tecnoburocracia e a economia", 1978 e por Bresser Pereira, no livro: Tecnoburocracia e contestação. Petrópolis, Ed. Vozes, 1972. 
(4) "O modelo de máquina escolar presente é o produto da relação entre diversas práticas discursivas

(máquinas abstratas) e relações de poder efetuadas em diversos agenciamentos, que configuraram toda a sociedade moderna". (GALVÃO, 2017, p. 266)

sua crítica por meio da produção científica e de outras formas de mobilização, como veremos mais adiante.

O texto está organizado na direção desse debate. Trata-se de um trabalho de base teórica construída com o suporte da fonte documental já indicada. (BRASIL, 2020a; BRASIL, 2020b; PAIXÃO, 2020; PALHARES, 2020) Nele são caracterizadas as formações discursivas articuladas em torno da interrupção ou não dos calendários escolares e dos possíveis modelos alternativos, além de uma discussão sobre como essas estratégias discursivas produzem modos de significação em torno do fechamento de sentidos e finalidades para escola, currículos e conhecimentos

\section{Racionalidade 1. Tempo é dinheiro: escola como máquina ${ }^{4}$ ainda que movida com baixa energia pedagógica.}

Escola, [....] uma máquina abstrata formada, em parte, pelos discursos referentes à criança e à necessidade de educá-la de acordo com certas finalidades sociais. (GALVÃO, 2017)

São muitos os trabalhos de pesquisadores do campo da educação dedicados a analisar os sentidos conceituais e os modos de organização e funcionamento da escola. (ARROYO; ABRAMOWICZ, 2009; FORQUIN, 1993; SANTOS GUERRA, 2002; SAVIANI, 2000, 2016) É consensual que essa secular instituição se universaliza na modernidade, especialmente no período pós revolução industrial para atender demandas de sociedades que rapidamente se urbanizam, engendram novas relações de trabalho e fortalecem suas dinâmicas de mercado com produtos e serviços cuja produção necessita mão de obra com níveis cada vez mais distintos de qualificação humana. É, portanto, uma instituição que se consolida fundamentalmente pela pressão do mundo do trabalho, e à semelhança dos demais modos de produção capitalista passa a conformar a organização e funcionamento de seus processos internos em função da expectativa de resultados e a configurar um importante espaço de agenciamento social em termos de governamentabilidade por parte do Estado.

Nesse duplo sentido, a escola se transforma num equipamento público pedagogicamente estruturado para responder predominantemente expectativas de profissionalização e de produção econômica, ao mesmo tempo que atua como máquina abstrata na produção biopolítica de subjetividades, disciplina e controle, 
conforme acentua Foucault (2001, 2002, 2009). O que tomamos de Galvão (2017) como epígrafe, pode ilustrar essa dupla finalidade: atendimento às exigências sociais e controle sobre a vida singular das pessoas. Entretanto, vale destacar que essas racionalidades não se efetivam socialmente sem movimentos de resistência e de lutas de grupos sociais por outras concepções.

Tragtenberg (2018) e Russo (2016), entre outros, falam sobre a existência de uma burocracia pedagógica que submete praticamente todos os processos escolares internos a racionalidades contextuais que engendram as relações sociais e a divisão do trabalho. Essa burocracia, que não se limita aos padrões da organização administrativa, pode ser traduzida também, por exemplo: nas chamadas reengenharias curriculares (GALLO, 2015); na rigidez das relações de tempo/espaços escolares (VIÑAO FRAGO, 2001); no disciplinamento dos corpos (FOUCAULT, 2009); na seletividade e meritocracia da avaliação (LUCKESI, 1995), no imperativo das regras e normas (SANTOS GUERRA, 2002), assim como em tantas outras formas de institucionalização das subjetividades humanas pela formação.

A noção de burocratização da prática educativa, de Sanches Vásquez (2003), como mais uma categoria teórica, talvez seja adequada para entendermos movimentos que nesse tempo de pandemia buscam preencher de sentidos a ideia de escola como lugar de produção de resultados objetivados, mensuráveis, úteis, enfim, como máquina que não pode parar. Mais importante que oportunizar socialmente as condições para a manutenção saudável da vida subjetiva das pessoas, é manter a escola no compasso do tempo kronos, um calendário que para alguns segmentos humanos é inescapável e inegociável.

Sobre burocracia, assim se expressa SánchezVásquez (2003, p. 333, tradução nossa)

A práxis se burocratiza onde quer que o formalismo ou o formulismo domine, ou mais exatamente, quando o formal se converte em seu próprio conteúdo. Na prática burocratizada o conteúdo é sacrificado pela forma, o real pelo ideal e o particular concreto pelo universal abstrato ${ }^{5}$.

O que está em jogo nessa correlação de forças entre distintos grupos frente as alternativas de manutenção (ou não) das escolas durante a pandemia, não é apenas a garantia de um calendário letivo ou a progressão sem interrupção de percursos formais da
(5) "La praxis se burocratiza dondequiera que el formalismo o el formulismo domina, o, más exactamente, cuando lo formal se convierte en su propio contenido. En la práctica burocratizada el contenido se sacrifica a la forma, lo real a lo ideal y lo particular concreto a lo universal abstracto." 
escolarização. Estes argumentos são os que aparecem na superfície, como um iceberg cujo volume alcança maior profundidade e envolve, portanto, a atribuição de determinados sentidos e finalidades à instituição e seus processos pedagógicos.

Tão logo as orientações dos órgãos de saúde passaram a recomendar o isolamento social com consequente fechamento de espaços que demandem aglomeração inclusive escolas, diferentes segmentos sociais se articularam no sentido de difundir alternativas de solução para manter o ensino funcionando. Assim, metodologias associadas a ideia de ensino a distância, ensino remoto, aulas on-line, ensino híbrido, etc., foram apresentadas como soluções para que sistemas e redes não interrompessem o calendário. Mas afinal, quais interesses mobilizam tamanha preocupação com o funcionamento das escolas? Que aspectos da formação humana ganham importância nesses movimentos?

Supõe-se que entre os interesses desses grupos estão a possibilidade de fazer avançar ainda mais rapidamente projetos que alinhem a educação aos interesses do mercado; a possibilidade de consolidação da educação a distância; a oportunidade para modernização associada a redução de custos; a substituição do trabalho docente por recursos tecnológicos; o monitoramento sobre processos e resultados escolares e a manutenção de certo controle sobre rotinas de vida de estudantes e suas famílias.

Argumentos protagonizados por segmentos sociais ligados à economia e ao mercado que se colocam em defesa de escolas movidas remotamente, carregam baixa substantividade pedagógica, especialmente no caso da Educação Básica, um nível de ensino que praticamente desconhece a experiência de ensino não presencial e que não teve qualquer preparo em relação às condições de infraestrutura seja ela material, técnica, docente ou didática. Mesmo na Educação Superior as condições objetivas são visivelmente limitadas para essa transposição.

Catini (2020) ressalta que a questão que se impõe nesse tempo de exceção são os meios para educar, mais que suas finalidades. Praticamente todo o debate sobre educação na pandemia tende a centrar-se em questões sobre educação a distância, ensino remoto, validação de horas de estudo, calendário e cargas didáticas. A pandemia e o confinamento aceleraram um processo que já em curso de introdução mais intensiva de tecnologias na relação educativa. 
Busca feita em ambientes virtuais de órgãos oficiais dos sistemas de ensino e de redes privadas, tornou possível verificarmos forte acolhimento de metodologias de ensino remoto nas redes de ensino da Educação Básica. Depoimentos de gestores educacionais do sistema público ilustram essa adesão, a exemplo do que informam, respectivamente, o Secretário de Estado da Educação do Maranhão e o do Distrito Federal:

O propósito foi colocar em prática, o quanto antes, estratégias para a continuidade do processo de aprendizagem dos estudantes, de forma não presencial, primando pelo acesso de todos, monitoramento e avaliação, durante o período de suspensão das atividades escolares, com o intuito de mitigar os riscos associados ao fechamento das escolas, como o próprio estudo da World Bank Group sugere. (MARANHÃO, 2020)

Uma nova experiência com o ensino mediado pela tecnologia estará disponível ao público a partir desta segunda-feira (6), quando, às 9h, na TV Justiça, estreia o programa Escola em Casa DF. Produzida pela Secretaria de Educação (SEE), a atração apresenta conteúdo que contempla desde a educação precoce ao ensino médio. (DISTRITO FEDERAL, 2020)

De modo geral, as iniciativas de sistemas públicos estão sendo incentivadas e suportadas tecnologicamente por empresas privadas ou organizações não estatais que já vêm ocupando territórios da Educação Básica pública, a exemplo da Fundação Lemann, Google (for Education), Todos pela Educação e tantas outras que, pela "janela de oportunidades frente ao caos" (GARRIDO, 2020, p. 1), se mostram interessadas em avançar ainda mais, inibindo-se por consequência, toda uma construção histórico-política de princípios e fundamentos da educação que servem de base pedagógica para definições no campo curricular e das próprias escolhas sobre o que deve contar como conhecimento na formação escolar.

\section{Racionalidade 2. Escola transbordante: funções que abarcam dimensão socioeducativa.}

Como apontamos na introdução, há uma segunda racionalidade construída sobre a base de uma concepção socioeducativa de escola compreendendo-a como um espaço que para além promover aprendizagens e desenvolvimento aos sujeitos, deve atuar como 
promotora de outras tarefas relacionadas a inclusão social, especialmente no que tange a redução de vulnerabilidades, desigualdades e violências. Em entrevista, Nóvoa (2012) comenta sobre o conceito que ele mesmo cunhou de "escola transbordante" e destaca que,

\begin{abstract}
Algumas instituições parecem caminhões enormes carregando toneladas, mas eles têm rodinhas de bicicleta no lugar de pneus grandes. A Educação assumiu muitas tarefas. É o fenômeno da escola transbordante. Alguém necessita fazer essas tarefas enquanto ninguém as quer e a escola tem de dar conta delas. Mas uma coisa é dizer que todas são missão da escola e outra é compreender que a instituição precisa cumpri-las enquanto outras esferas da sociedade não estiverem fortes. Quando isso ocorrer, teremos um compartilhamento que chamo de espaço público da Educação.
\end{abstract}

No Brasil pós constituição de 1988, a prerrogativa do direito socioeducativo foi garantida pela promulgação do Estatuto da Criança e do Adolescente (ECA), em 1990 e complementada com a criação da lei do Sistema Nacional de Atendimento Socioeducativo (SINASE) que regulamentou medidas socioeducativas em todo o território nacional. Essa informação serve tão somente para apontarmos a legislação que serve de base para um regime de articulação entre os órgãos oficiais da educação, da saúde, assistência social, cultura e esporte, visando maior integração no desenvolvimento de crianças e adolescentes no país.

No contexto da pandemia e do consequente distanciamento social, as escolas são chamadas a cumprir esse papel, razão pela qual sistemas públicos de ensino, quando optam por manter o ensino no modo remoto, devem responsabilizar-se por formas alternativas de acesso universal às condições objetivas de continuidade do processo escolar para todos/as os/as estudantes. Organizações não governamentais e de assistência social ligadas a educação que atuam no fortalecimento dessa concepção de formação, tendem a acolher soluções instrumentais e tecnológicas oferecidas pelos setores privados para substituir o ensino presencial pelo remoto, contanto que se cumpram medidas básicas de inclusão social, entre as quais o acesso a alimentação, aos materiais escolares, as ferramentas tecnológicas, etc. 


\section{Racionalidade 3. Discursos em torno da concepção de escola como lugar de direitos universais à aprendizagem e ao desenvolvimento humano.}

No extenso repertório da produção científica construído historicamente por pesquisadores e docentes envolvidos com o campo da educação e particularmente do currículo, encontra-se um conjunto importante de fundamentos, princípios e conceitos que servem de base tanto para a composição de projetos curriculares na formação escolar e acadêmica, quanto para investigação e debates teóricos em torno de sentidos que são atribuídos à escola, currículos e conhecimentos. Forma parte desse repertório uma produção igualmente significativa construída com base em uma concepção crítica de educação (igualmente ampla e diversa), da qual também derivam determinados fundamentos, conceitos e princípios que ancoram formações discursivas em torno de significantes visivelmente marcados sobre esses mesmos conceitos (de escola, currículos e conhecimentos).

O que estamos denominando aqui como "concepção crítica", tem a ver com uma filiação teórica que não se limita aos princípios e conceitos da Teoria Crítica e das chamadas teorias críticas de currículo. (ZANK; RIBEIRO; BEHAR, 2015) Abarca um universo teórico mais amplo de epistemologias que, a seu modo, concebem a educação na perspectiva da crítica social, histórica e política. Trata-se de uma denominação que serve estritamente para designar marcos teóricos que notadamente se contrapõem aos fundamentos, princípios e conceitos das filosofias consideradas liberais, neoliberais, positivistas e pragmáticas. São, em geral, abordagens que se ancoram em perspectivas sócio-históricas, socioconstrutivistas, histórico-culturais ou histórico-críticas.

Não obstante operarem com marcos conceituais distintos, essas epistemologias se aproximam ou até mesmo se encontram em torno de fundamentos e princípios relativamente comuns, entre os quais podemos destacar, a título de exemplo, entendimentos sobre a relação educação-trabalho, escola-democracia, formação-emancipação, ciência-conhecimento-cultura, aprendizagem-desenvolvimento, currículo-tecnologia, direito-educação, além de possíveis outros. Todas assumem como princípio fundante a ideia de educação como bem público que se integra a produção histórica dos sujeitos e a escolarização é vista como parte desse acúmulo coletivo. 
É nesse âmbito que se fortalecem formações discursivas em torno da concepção de escola como um lugar social e cultural de materialização e, portanto, de garantia de direitos universais à aprendizagem e ao desenvolvimento humano nos planos individual e coletivo. Uma escola que deve estruturar-se orientada por currículos pedagogicamente bem desenhados, suportados por conhecimentos acadêmicos e culturais relevantes, potencialmente indutores de trajetórias formativas consistentes e sincronizadas com expectativas e demandas da vida contemporânea.

Nesse momento de pandemia, são os segmentos comprometidos com essa concepção de educação, de escola, de currículo e de conhecimento, que fazem principal resistência aos modelos tecnocratizantes, aligeirados, seletivos, meritocráticos, pedagogicamente frágeis e com tendências privatizantes para atividades de ensino. Seja nos espaços acadêmicos, nas escolas ou na sociedade mais ampla, esses grupos vêm assumindo e difundindo discursos em defesa de alternativas que se pautem em fundamentos e princípios pedagogicamente consistentes, que não abram mão de premissas como:

a. acesso universal às ferramentas tecnológicas, às redes virtuais, aos materiais e demais insumos didáticos;

b. acesso, também universal, ainda que básico, às condições objetivas da vida cotidiana tais como alimentação, ambientes de estudo e assistência à saúde e

c. acesso não seletivo à processos, minimamente qualificados de ensino, aprendizagem e interação, ainda que estes sejam realizados emergencialmente em modos não presenciais.

Entre as preocupações manifestadas especialmente por docentes, pesquisadores e instituições está a de que a emergencialidade desse momento possa converter-se numa ampla porta de entrada para a adoção permanente de modelos de ensino remoto em larga escala, o que representaria possibilidades, por exemplo, de redução de custos públicos na educação, consolidação da chamada educação a distância em redes públicas, indução à privatização e substituição paulatina do trabalho educativo dos professores por formas instrumentais de mediação tecnológica. Em razão desses riscos, esse coletivo defende, entre outros aspectos, que a adoção de modelos não presenciais esteja estreitamente vinculada à ideia de emergencialidade, excepcionalidade, condicionalidade e autonomia relativa. 
(UNIVIVERSIDADE FEDERAL DE SANTA CATARINA, 2020) Desse modo, é fundamental que sejam preservadas, no pós-pandemia, as formas presenciais de ensino e aprendizagem, sustentadas por processos pedagógicos cientificamente reconhecidos e atendidas as condições básicas para sua efetivação com relativa autonomia didática e de concepção pedagógica aos professores e instituições. Que a experiência desse tempo emergencial não sirva como mais um sutil mecanismo de aprofundamento das desigualdades educacionais e sociais tão fortemente marcadas na sociedade brasileira.

É, pois, no sentido dessa defesa que associações científicas e instituições de ensino vêm manifestando seus posicionamentos, a exemplo da nota publicada pela Rede Escola Pública e Universidade (REPU) e Grupo Escola Pública e Democrática (GEPUD) assinada por $29^{6}$ entidades ligadas à educação pública brasileira e de algumas outras manifestações que destacamos em excertos no Quadro 1 , a seguir.

Quadro 1 - Manifestações públicas de entidades científicas e educacionais referentes ao funcionamento de escolas durante a pandemia do COVID-19

\begin{tabular}{|c|c|c|}
\hline $\begin{array}{l}\text { Instituição/ } \\
\text { Pesquisador/a }\end{array}$ & Síntese da Nota/Carta/Artigo & Fonte \\
\hline $\begin{array}{l}\text { Associação Na- } \\
\text { cional de Pesqui- } \\
\text { sa e Pós-Gradua- } \\
\text { ção em Educação } \\
\text { (Anped) }\end{array}$ & $\begin{array}{l}\text { Redes e pesquisadores lançam Nota Técnica para } \\
\text { fomentar transparência e monitoramento ativo das } \\
\text { políticas educacionais de caráter emergencial. } \\
\text { [...] O documento recomenda o reforço da gestão } \\
\text { democrática para a avaliação das políticas emer- } \\
\text { genciais, a identificação de casos de discriminação } \\
\text { educacional e para a reparação do direito à educa- } \\
\text { ção dos/as estudantes na reabertura das escolas }\end{array}$ & $\begin{array}{l}\text { Portal } \\
\text { Anped }\end{array}$ \\
\hline $\begin{array}{l}\text { Confederação } \\
\text { Nacional dos } \\
\text { Trabalhadores em } \\
\text { Educação (CNTE) }\end{array}$ & $\begin{array}{l}\text { A Confederação Nacional dos Trabalhadores em } \\
\text { Educação (CNTE) lançou dia 18/06 as "Diretrizes } \\
\text { para a Educação Escolar durante e pós-pandemia } \\
\text { - contribuições da CNTE". "O material propõe estra- } \\
\text { tégias de retomada das aulas com foco na defesa } \\
\text { da vida e contra as desigualdades na educação, } \\
\text { mantendo a escola pública brasileira como espaço } \\
\text { de efetivo direito à aprendizagem dos/as estudantes } \\
\text { e de exercício permanente da cidadania." }\end{array}$ & $\begin{array}{l}\text { Freitas } \\
\text { (2020). }\end{array}$ \\
\hline
\end{tabular}

(6) Assinam a nota: Ação Educativa Associação Brasileira de Ensino de Biologia (SBEnBio) Associação Brasileira de Ensino de Ciências Sociais (ABECS), UR, São Paulo; Associação Nacional de História - Seção São Paulo (Anpuh-SP); Associação Nacional de Pesquisadores em Financiamento da Educação (Fineduca); Associação Nacional de Política e Administração da Educação (Anpae); Associação Nacional de Pós-Graduação e Pesquisa em Educação (ANPEd) Associação Nacional de Pós-

Graduação em Filosofia (Anpof); Associação Nacional pela

Formação dos Profissionais da Educação (Anfope); Centro de

Estudos Educação e Sociedade (Cedes); Coletivo Proposta pela Educação - Santo André/ SP; Comitê SP da Campanha Nacional pelo Direito à Educação; Conselho Regional de Psicologia de São Paulo; Escola Dieese de Ciências do Trabalho; Federação dos Professores do Estado de São Paulo (Fepesp); Fórum Municipal de Educação de São Bernardo do Campo; Fórum Nacional de Coordenadores Institucionais do Parfor (Forparfor); Fórum Nacional de Diretores de Faculdades/ Centros/Departamentos de Educação ou Equivalentes das Universidades Públicas Brasileiras (Forumdir); Fórum Nacional dos Coordenadores Institucionais do PIBID e Residência Pedagógica (ForpibidRP); Grupo Interinstitucional de Queixa Escolar Juventude do Movimento dos Trabalhadores Sem-Teto (MTST); Movimento de Ativistas Sociais de Santo André (Massa); Movimento Independente Mães de Maio; Movimento Nacional em Defesa do Ensino Médio; Rede Ubuntu de Educação Popular; Sindicato dos Professores do Ensino Oficial do Estado de São Paulo (Apeoesp); Sindicato Nacional dos Docentes das Instituições de Ensino Superior (Andes-SN); Sindicato Nacional dos Servidores Federais da Educação Básica, Profissional e Tecnológica (Sinasefe); Sindicato Nacional dos Servidores Federais da Educação Básica, Profissional e Tecnológica, Seção São Paulo (Sinasefe-SP); União Municipal dos Estudantes Secundaristas (UMES) - Santo André/SP. 


\begin{tabular}{|c|c|c|}
\hline $\begin{array}{l}\text { Universidade Fe- } \\
\text { deral de Juiz de } \\
\text { Fora (UFJF). Gru- } \\
\text { pos de Pesquisa } \\
\text { da Faculdade de } \\
\text { Educação }\end{array}$ & $\begin{array}{l}\text { Manifestação relativa ao programa "estude em } \\
\text { casa" da secretaria de estado de educação (SEE) } \\
\text { de Minas Gerais. "[...] A Faculdade de Educação da } \\
\text { Universidade Federal de Juiz de Fora, por meio de } \\
\text { seus grupos de pesquisa, vem manifestar-se sobre } \\
\text { o Programa "Estude em Casa" como regime de es- } \\
\text { tudo não presencial dirigido aos/às estudantes dos } \\
\text { ensinos fundamental e médio, bem como aos/às } \\
\text { professores/as da rede estadual de ensino de MG, } \\
\text { enquanto durar a pandemia COVID-19. O que, em } \\
\text { princípio, parece ser uma resposta ao cumprimento } \\
\text { do calendário letivo frente ao isolamento social, } \\
\text { configura-se como um instrumento de precarização } \\
\text { da educação escolar por vários motivos. }\end{array}$ & $\begin{array}{l}\text { Portal } \\
\text { UFJF }\end{array}$ \\
\hline $\begin{array}{l}\text {-Fórum Nacional } \\
\text { de Educação do } \\
\text { Campo (FONEC) }\end{array}$ & $\begin{array}{l}\text { Em síntese, embora a oferta de atividades remotas } \\
\text { possa ser considerada importante para manter os } \\
\text { estudantes ativos nos casos onde isto é possível, } \\
\text { para além de todo o sofrimento e desafios da pan- } \\
\text { demia, tais atividades não podem ser contadas } \\
\text { como dias letivos e nem serem objeto de avaliação, } \\
\text { visto produzirem uma enorme desigualdade, em } \\
\text { função das imensas diferenças de acesso à tais } \\
\text { conteúdos escolares disponibilizados desta forma. } \\
\text { Pois, isto fere frontalmente o princípio da "Igualda- } \\
\text { de de condições para o acesso e permanência na } \\
\text { escola", disposto no inciso I do Artigo } 206 \text { da Cons- } \\
\text { tituição Federal. }\end{array}$ & $\begin{array}{l}\text { Portal UR } \\
\text { FGS }\end{array}$ \\
\hline $\begin{array}{l}\text { UFBA - Universi- } \\
\text { dade Federal da } \\
\text { Bahia (UFBA) } \\
\text { Grupo de pes- } \\
\text { quisa Educação, } \\
\text { Comunicação e } \\
\text { Tecnologia (GEC) }\end{array}$ & $\begin{array}{l}\text { Com a pandemia esse o processo de precarização } \\
\text { da educação pública ganha força ao ser incorpora- } \\
\text { do pelo governo como solução para a dificuldade } \\
\text { de oferta presencial. (....) As tentativas de escolas } \\
\text { e universidades de fazerem o que estão chamando } \\
\text { eufemisticamente de ensino remoto já estão reve- } \\
\text { lando depoimentos alarmantes. }\end{array}$ & $\begin{array}{l}\text { Portal } \\
\text { UFBA }\end{array}$ \\
\hline
\end{tabular}

Fonte: elaborado pelo autor (2020).

As questões de fundo levantadas por esses grupos frente a potencial velocidade em que se apresentam as soluções para manter atividades de ensino funcionando, não se limitam à discussão sobre a necessidades e modelos de alternativas emergenciais ou efetivação de calendários escolares. Referem-se principalmente aos sentidos que estão sendo atribuídos por certos grupos à escolarização e consequentemente à formação, assim como aos interesses que mobilizam discursos movidos nessa direção. Notadamente, as opções de funcionamento imediato de escolas pela instrumentação técnica e burocrática, soluções aparentemente céleres, inovadoras e eficientes, mascaram concepções e interesses em relação ao 
fechamento de outros sentidos sociais para escola, currículos e conhecimentos.

Não por acaso, textos acadêmicos (CATINI, 2020; KRAWCZYK, 2020; XIMENES, 2020;) e manifestações de instituições e associações educativas (CNTE, 2020; ANFOP, 2020; ASSOCIAÇÃO NACIONAL DE PESQUISA E PÓS-GRADUAÇÃO, 2020) vêm problematizando a proposição de medidas que simplesmente projetam a transposição mecânica de modelos curriculares de escolarização presencial (com todas as suas fragilidades históricas) a outros, não presenciais, que tendem a fragilizar e precarizar ainda mais a formação. Nesse sentido, são trazidas ao debate questões relacionadas aos riscos de segregação, exclusão e discriminação de estudantes; privatização e mercadorização do ensino; instrumentação e tecnificação de metodologias e processos pedagógicos; ampliação de desigualdades educacionais, cognitivas e sociais; meritocratização e estandardização da aprendizagem e da avaliação; ampliação do gerencialismo em detrimento da gestão democrática, além de outros.

Alertas em relação aos riscos são feitos inclusive pelo Conselho Nacional de Educação no Parecer n ${ }^{0}$ 05/2020 que trata da reorganização do calendário escolar e da possibilidade de cômputo de atividades não presenciais para fins de cumprimento da carga horária mínima anual, em razão da pandemia da COVID-19. Não obstante, cabe acentuar que tanto o referido parecer, quanto a Medida Provisória no 934/2020 do Ministério da Educação (MEC), no seu conjunto, "buscam dar um ar de legalidade ao improviso, quando autorizam a continuidade do ano letivo via ensino remoto ou não presencial" (XIMENES, 2020, p. 1)

No Parecer $n^{\circ}$ 05/2020 do CNE, lê-se que:

E importante considerar as fragilidades e desigualdades estruturais da sociedade brasileira que agravam o cenário decorrente da pandemia em nosso país, em particular na educação, se observarmos as diferenças de proficiência, alfabetização e taxa líquida de matrícula relacionados a fatores socioeconômicos e étnico-raciais. Também, como parte desta desigualdade estrutural, cabe registrar as diferenças existentes em relação às condições de acesso ao mundo digital por parte dos estudantes e de suas famílias. Além disso, é relevante observar as consequências socioeconômicas que resultarão dos impactos da COVID-19 na economia como, por exemplo, aumento da taxa de desemprego e redução da renda familiar. Todos estes aspectos demandam um olhar cuidadoso para as 
propostas de garantia dos direitos e objetivos de aprendizagem neste momento a fim de minimizar os impactos da pandemia na educação. (BRASIL, 2020, p. 3)

Por meio dos textos oficiais antes referidos, observa-se que nesse tempo de pandemia o Estado Brasileiro, a exemplo do que fazem o MEC, o CNE, além de várias secretarias estaduais e municipais de educação, constrói suas narrativas em estreita convergência com as defesas feitas por grupos privados que se mobilizam em favor da substituição imediata do ensino presencial pelo remoto. Não obstante responderem pela gestão da educação pública com a responsabilidade da universalização desse direito social à população, seus alinhamentos com racionalidades e interesses privados mostram-se cada vez mais evidentes. É predominantemente sobre estes aspectos de fundo político que os tensionamentos entre as diferentes concepções se acentuam.

\section{Palavras finais}

Notadamente, o contexto social e político que presenciamos nesse tempo de pandemia, impõe com mais força interrogações sobre os projetos de sociedade que se colocam como horizonte de futuro, sobre validez e factibilidade das metanarrativas que foram sendo hegemonizadas ao longo da modernidade e do contemporâneo em relação a conceitos como ciência, democracia, liberdade, cultura, justiça, formação, direitos humanos, trabalho e tanto outros; e ainda, sobre os sentidos sociais de educação, escola, currículo e conhecimentos. Cenários desafiantes e de crise como esse que vivemos, tendem a romper com o que está instituído, razão pela qual os tensionamentos, sejam eles derivados de concepções políticas, epistemológicas ou de crenças, ganham maior intensidade, especialmente porque, via de regra, são trazidos para o centro das disputas nos processos decisórios.

Instituições, pesquisadores, docentes e demais profissionais comprometidos com a concepção crítica de educação e formação, seguem, durante a pandemia, atuando em defesa dessa epistemologia, seja difundindo seus princípios e por meios de lives, notas públicas, eventos acadêmicos virtuais e por outras redes de contato, ou ainda por meio da participação em grupos de trabalho, comitês, fóruns e demais espaços institucionais com alguma repercussão em instâncias decisórias. Para esse grupo, os sentidos sociais da 
educação, da formação, dos currículos e dos conhecimentos estão marcadamente relacionados com a ideia de um projeto de humanidade que coloca o cuidado com a vida singular e coletiva acima dos interesses da economia.

\title{
School, curriculum and knowledge: meanings in dispute because of the pandemic
}

\begin{abstract}
This article analyzes some social meanings attributed to schools, curriculums and knowledge in this time of pandemic, especially due to the proposition of non-face-to-face models for the teaching. In this context, discuss the correlations of force mobilized by various groups or social segments involved with education that assuming different concepts and interests in the debate about meanings and purposes for school formation. This is an empiric-theoretical study that explores official documents, academic texts and information from the press found in digital environments. It is affirmed that this interplay of forces places in dispute three rationalities: a neoliberal one that conceives of schools as machines for production of objective results, another based on the idea of schools as socio-educational spaces for the reduction of inequalities, and a third that understands schools as places for human education and as institutions for promoting the universal right to learning and human development.
\end{abstract}

Keywords: Teaching. Curriculum. Knowledge. Pandemic.

\section{Escuela, currículo y conocimientos: sentidos tensionados en contextos de pandemia.}

\begin{abstract}
Resumen: En el texto se analizan algunos significados sociales atribuidos a las escuelas, currículos y conocimientos en este tiempo de pandemia, especialmente por la proposición de modelos de enseñanza no presencial. En este contexto, se discuten las correlaciones de fuerza movilizadas por diferentes grupos o segmentos sociales vinculados a la educación, los cuales buscan marcar distintas concepciones e intereses en el debate sobre significados y propósitos para la formación escolar. Constituye un trabajo empírico-teórico, que explora como fuentes: documentos oficiales, textos académicos e informaciones de prensa disponibles en espacios digitales. Se afirma que este juego de fuerzas pone en disputa tres racionalidades: una que tiene bases neoliberal y que concibe a la escuela como una máquina para producir resultados objetivos; otra anclada en la idea de la escuela como un espacio socioeducativo, por lo tanto, actúa para reducir desigualdades; y una tercera que entiende la escuela como un lugar de formación humana y una institución que promueve el derecho universal al aprendizaje y al desarrollo humano.
\end{abstract}

Palabras clave: Enseñanza. Currículo. Conocimiento. Pandemia.

\section{Referências}

ARROYO, M.; ABRAMOWICZ, A. A reconfiguração da escola: entre a negação e a afirmação de direitos. São Paulo: Papirus, 2009. 
ASSOCIAÇÃO NACIONAL DE PESQUISA E PÓS-GRADUAÇÃO. Redes e pesquisadores lançam Nota Técnica para fomentar transparência e monitoramento ativo das políticas educacionais de caráter emergencial. Rio de Janeiro, RJ: ANPED, 2020. Disponível em: https://anped.org. $\mathrm{br} /$ news/redes-e-pesquisadores-lancam-nota-tecnica-para-fomentartransparencia-e-monitoramento-ativo-das. Acesso em: 27 jun. 2020.

ASSOCIAÇÃO NACIONAL PELA FORMAÇÃO DOS PROFISSIONAIS DA EDUCAÇÃO - ANFOPE. Posicionamento sobre o Parecer do CNE que trata da Reorganização dos Calendários Escolares e a realização de atividades pedagógicas não presenciais durante o período de Pandemia da COVID-19. Disponível em: http://www.anfope.org.br/wpcontent/uploads/2020/04/1.-Nota-das-entidades-nacionais-ref-ParecerCOVID-19.pdf. Acesso em: 28 jun.2020.

BRASIL. Parecer 05/2020. Reorganização do Calendário Escolar e da possibilidade de cômputo de atividades não presenciais para fins de cumprimento da carga horária mínima anual, em razão da Pandemia da COVID-19. Brasília, DF: Conselho Pleno, 2020. Disponível em: http://portal.mec.gov.br/index.php?option = com_docman\&view = downloadEalias = 145011-pcp005-20Ecategory_slug = marco-2020pdfÉ Itemid $=30192$. Acesso em: 15 ago. 2020a.

BRASIL. Parecer 11/2020. Orientações Educacionais para a Realização de Aulas e Atividades Pedagógicas Presenciais e Não Presenciais no contexto da Pandemia. Brasília, DF: Conselho Pleno, 2020. Disponível em: http://portal.mec.gov.br/index.php?option =com_docman\&vie $\mathrm{w}=$ downloadEalias = 148391-pcp011-20\&category_slug = julho-2020pdfEItemid $=30192$. Acesso em 15 ago. 2020b.

CATINI, C. O trabalho de educar numa sociedade sem futuro. São Paulo: Boitempo. 2020. Disponível em: https://blogdaboitempo.com. br/2020/06/05/o-trabalho-de-educar-numa-sociedade-sem-futuro/. Acesso em: 25 jun. 2020.

CONFEDERAÇÃO NACIONAL DOS TRABALHADORES EM EDUCAÇÃO. Diretrizes para a Educação Escolar durante e pós-pandemia. Brasília, DF: CNTE, 2020. Disponível em: https://avaliacaoeducacional. files.wordpress.com/2020/06/cntediretrizespandemia.pdf. Acesso em: 23 jun. 2020.

DE LUCA PRETTO, N.; SILVEIRA BONILLA, M. H.; SOUSA SENA, I. P. F. de. Educação em tempos de pandemia: reflexões sobre as implicações do isolamento físico imposto pela COVID-19. Salvador: Grupo de pesquisa, educação, comunicação e tecnologias, 2020. Disponível em: https://blog.ufba.br/gec/files/2020/05/GEC_livro_final_imprensa.pdf. Acesso em: 24 jun. 2020.

FÓRUM NACIONAL DA EDUCAÇÃO DO CAMPO. Pela reorganização do calendário escolar sem ensino remoto: em defesa do direito à educação do campo. [S. 1]: FONEC, 2020. Disponível em: https://www.ufrgs.br/ liceducampofaced/wp-content/uploads/2020/06/NOTA-FONEC-Pela- 
Reorganizac\%CC\%A7a\%CC\%83o-do-Calenda\%CC\%81 rio-Escolar-semEnsino-Remoto.pdf. Acesso em: 23 jun. 2020.

FORQUIN, J.-C. Escola e cultura. Porto Alegre: Artes Médicas, 1993.

FOUCAULT, M. Microfísica do coder. Rio de Janeiro: Edições Graal, 2001.

FOUCAULT, M. Vigiar e punir: nascimento da prisão. Rio de Janeiro: Vozes, 2009.

FOUCAULT, M. Vigiar e punir: nascimento da prisão. Tradução de Taquel Ramalhete. Petrópolis: Vozes, 2002.

FREITAS, L. C. de. CNTE divulga diretrizes para a pandemia.

[S. l.]: Avaliação Educacional, [2020]. Disponível em: https:// avaliacaoeducacional.com/author/freitaslc/. Acesso em: 20 jun. 2020.

GALLO, S. Educação menor: produção de heterotopias no espaço escolar. In: GRUPO TRANSVERSAL. Educação menor: conceitos e experimentações. Curitiba: Appris, 2015.

GALVÃO, B. A. Foucault, Deleuze e a máquina escolar: a escola como dispositivo de poder e a produção de corpos dóceis. Revista Ideação, Feira de Santana, Edição Especial, 2017. Disponível em: http:// periodicos.uefs.br/index.php/revistaideacao/article/view/2996. Acesso em: 30 jun.2020.

GARRIDO, F. O uso da pandemia para precarizar a educação pública através de plataformas digitais. Brasil de Fato, Belo Horizonte, 1 abr. 2020. Disponível em: https://www.brasildefatomg.com.br/2020/04/01/ o-uso-da-pandemia-para-precarizar-a-educacao-publica-atraves-deplataformas-digitais. Acesso em: 26 jun. 2020.

GEBARA, J. J. Algumas considerações sobre o estado, a tecnoburocracia e a economia. São Paulo: Revista de administração de empresas, v. 18, n. 1, jan./mar. 1978. Disponível em: https://www.scielo.br/scielo. php? script $=$ sci_arttextÉpid $=$ S0034-75901978000100010. Acesso em: 30 jun. 2020.

GIROUX, H. Teoria crítica e resistência em educação. Petrópolis: Vozes, 1986.

DISTRITO FEDERAL. Aulas estão suspensas, mas aprendizagem não pode parar. Coronavirus, Agencia Brasília, Brasília, DF, 5 abr. 2020. Disponível em: https://www.agenciabrasilia.df.gov.br/2020/04/05/ aulas-estao-suspensas-mas-aprendizagem-nao-pode-parar/. Acesso em: 25 jun. 2020.

MARANHÃO. A educação durante a pandemia. Secretaria de Educação, São Luis: SEDUC, 29 mar. 2020. Disponível em: https://www.educacao. ma.gov.br/a-educacao-durante-a-pandemia/. Acesso em: 26 jun. 2020.

KRAWCZYK, N. As falácias da Educação à Distância se alastram com (e como) o COVID-19. Carta Maior, [s. l.], 31 maio. 2020. Disponível em: https://www.cartamaior.com.br/?/Editoria/Educacao/As-falacias-da- 
Educacao-a-Distancia-se-alastram-com-e-como-o-Covid19/54/47657. Acesso em: 22 jun. 2020.

LUCKESI, C. C. Avaliação da aprendizagem escolar: estudos e proposições. São Paulo: Cortez, 1995.

PAIXÃO, A. Só 6 das 69 universidades federais adotaram ensino a distância após paralisação por causa da Covid-19. Portal G1, Rio de Janeiro, RJ, 15 maio 2020. Disponível em https://g1.globo.com/ educacao/noticia/2020/05/14/so-6-das-69-universidades-federaisadotaram-ensino-a-distancia-apos-paralisacao-por-causa-da-covid-19. ghtml. Acesso em: 15 ago. 2020.

PALHARES, I. 60\% das Universidades Federais rejeitam ensino a distância durante quarentena. Folha de São Paulo, São Paulo, 31 mar. 2020. Disponível em: https://www1.folha.uol.com.br/ educacao/2020/03/60-universidades-federais-rejeitam-ensino-adistancia-durante-quarentena.shtml. Acesso em: 15 ago. 2020.

PORTILHO, G.; VICHESSI, B. Entrevista com o educador português António Nóvoa. Revista Nova Escola, [s. l.], 01 out. 2012. Disponível em: https://novaescola.org.br/conteudo/212/entrevista-educadorportugues-antonio-novoa. Acesso em: 28 jun. 2020.

PEREIRA, L. C. B. Tecnoburocracia e contestação. Petrópolis: Vozes, 1972.

REDE ESCOLA PÚBLICA E UNIVERSIDADE; GRUPO ESCOLA PÚBLICA E DEMOCRÁTICA. O ensino não presencial e o aumento das desigualdades Educacionais: ninguém pode ser excluído. Nota pública, [s. 1], 21 maio 2020. Disponível em: https://3c60c040-0201-4188-bfd9ddc208c6ad1a.filesusr.com/ugd/9cce30_9970830dcec248b98f25e43470cf 3d99.pdf. Acesso em: 24 jun. 2020.

RUSSO, M. H. Planejamento e burocracia na prática escolar: sentidos que assumem na escola pública. RBPAE, Brasília, DF, v. 32, n. 1, p. 193-210 jan./abr, 2016. Disponível em: https://seer.ufrgs.br/rbpae/ article/view/62356\#: :text = A\%20partir\%20de\%20relato\%20 extra\%C3\%ADdo,daquele \%20processo \% 20numa\%20escola \%20 p\%C3\%BAblica. Acesso em: 30 jun. 2020.

SÁNCHEZ VÁSQUEZ, A. Filosofía de la práxis. Argentina: Siglo XXI Editores, 2003.

SANTOS GUERRA, M. Á. Entre bastidores: o lado oculto da organização escolar. Porto, PT: Editora Asa, 2002.

SAVIANI, D. Educação escolar, currículo e sociedade: o problema da Base Nacional Comum Curricular. Movimento Revista de Educação, Niterói, n. 4, 2016. Disponível em: https://periodicos.uff.br/ revistamovimento/article/view/32575. Acesso em: 5 jul. 2020.

SAVIANI, D. Educação: do senso comum à consciência filosófica. 13 ed. Campinas: Autores Associados, 2000. 
TRAGTENBERG, M. A escola como organização complexa. Educação Sociedade, Campinas, v. 39, n. 142, p. 183-202, jan./mar, 2018.

Disponível em: https://www.scielo.br/scielo.php?script = sci_arttext\&pi $\mathrm{d}=$ S0101-73302018000100183. Acesso em: 15 jul. 2020.

UNIVERSIDADE FEDERAL DE JUIZ DE FORA. Grupos da FACED/ UFJF Manifestação relativa ao programa "Estude em Casa".

Minas Gerais: UFJF, 2020. Disponível em: https://www.ufjf.br/ faculdadedeeducacao/2020/05/21/grupos-da-facedufjf-manifestam-seem-relacao-ao-programa-estude-em-casa/. Acesso em: 25 jun. 2020.

UNIVIVERSIDADE FEDERAL DE SANTA CATARINA. Subcomitê Acadêmico elabora diagnóstico institucional, proposta de Resolução e de Calendário Suplementar Excepcional. Santa Catarina: Notícias UFSC, 2020. Disponível em: https://noticias.ufsc.br/2020/06/subcomiteacademico-elabora-diagnostico-institucional-proposta-de-resolucao-e-decalendario-suplementar-excepcional/. Acesso em: 26 jun. 2020.

VIÑAO FRAGO, A. Do espaço escolar e da escola como lugar: propostas e questões. In: VIÑAO FRAGO, A.; ESCOLANO, A. Currículo, espaço e subjetividade: a arquitetura como programa. Tradução de Alfredo VeigaNeto. 2. ed. Rio de Janeiro: DPEA, 2001.

XIMENES, S. Ironicamente, o mesmo Estado que pressiona por continuar as rotinas de avaliação nas escolas resiste em se submeter à avaliação quanto às políticas públicas que adota. 04 maio. 2020. Disponível em: http://www.epsjv.fiocruz.br/noticias/entrevista/ ironicamente-o-mesmo-estado-que-pressiona-por-continuar-rotinasde-avaliacao-nas?fbclid = IwAR2Q8BWixosH85Y0jJVZ6mgLahTbRcHrpuHh_mZJte0tmpo4VKthk-11KI. Acesso em: 24 jun. 2020.

ZANK, C.; RIBEIRO, J. A. R.; BEHAR, P. A. O significado de crítica e sua relação com a concepção de educação. Rio de Janeiro: Currículo sem Fronteiras, v. 15, n. 3, p. 851-877, set./dez. 2015. Disponível em: http:// www.curriculosemfronteiras.org/vol15iss3articles/zank-ribeiro-behar. pdf. Acesso em: 15 jul. 2020. 